\title{
Study of the Soiled Places and Effects of the Harmful Factors Topography on the Special Clothing for Chemical Enterprises Workers
}

\section{Damira R. ZIYATDINOVA}

Lecturer

Faculty of Textile Industry Technology and Fashion Textile Industry Materials and Technologies Department

Kazan National Research Technological University 68, Karl Marks Str., Kazan, 420015, Russia damira10ziyat@mail.ru

\section{Lyudmila N. ABUTALIPOVA \\ Ph.D. (in Technical Sciences) \\ Professor}

Textile Industry Materials and Technologies Department head

Faculty of Textile Industry Technology and Fashion

Kazan National Research Technological University

68, Karl Marks Str., Kazan, 420015, Russia abutalipo@mail.ru

\section{Mayya R. ZIGANSHINA}

Ph.D. (in Chemical Sciences)

Associate Professor

Faculty of Textile Industry Technology and Fashion Textile Industry Materials and Technologies Department

Kazan National Research Technological University

68, Karl Marks Str., Kazan, 420015, Russia zigmay4@mail.ru

\section{Azizbek Sh.u. SHERALIEV}

Graduate Student

Faculty of Textile Industry Technology and Fashion

Textile Industry Materials and Technologies Department

Kazan National Research Technological University

68, Karl Marks Str., Kazan, 420015, Russia

aziikooo@mail.ru

\begin{abstract}
Chemical production processes present a potential risk of poisoning and illness for workers. The special clothing that is resistant to chemicals and provides a reliable barrier against the penetration of toxic gases, dust and aerosol filtration is used for purpose of occupational safety ensure measures. The authors performed an analysis of the requirements, formulated for fabrics, design, and manufacturing technology of the chemical protective clothing. The decrease in the level of fabrics quality indicators in special clothing of chemical enterprises workers is associated with the harmful production factors influenceis particularly mechanical, physical-chemical, biological, complex factors. The article describes study of the fabrics soiled places and damage topography as a result of exposure to harmful chemicals, industrial fluids, oil products, oils, abrasion, tensile and
\end{abstract}


tearing effects. There is a solution is proposed for the design of special clothing, based on the account possible areas of fabrics and seams damage.

Keywords: special clothing; protective clothing; textile fabric; damage; topography; chemicals; abrasion; stretching; tearing; construction; protective pads.

\section{Introduction}

The wide range of production and transportation enterprises processes poses a potential danger of poisoning and illness of workers. Particularly, chemical methods of processing raw fabrics and chemical fabrics, enterprises carrying out storage, transportation of chemicals as well as emergency situations are the potential danger for chemical-related illness. It is necessary to use personal protective equipment to ensure the protection of the life and health of workers in the chemical industry. This equipment includes special chemicals resistant clothing and providing a reliable barrier against the penetration of toxic gases or filtering dust particles and aerosols (Rozdin, Varenik, Khabarova, 2006).

There is a certain range of special clothing for this purpose: completely sealed insulating suits, overalls suits consisting of jackets, trousers or semi-overalls, dressing gowns, aprons, arm sleeves, etc. (Khalil, 2015; Ziyatdinova, Abutalipova, Vasilyeva, 2019). The choice of personal protective equipment for workers should be accompanied by a balance between the usability and necessary adequate level of protection and the requirements of ergonomics ensuring (Havenith, Hartog, Martini, 2011; Sung, Hsu, Lou, 2015).

The problem of deterioration of the chemical special clothing usability and protective properties before the end of standard usage time occurs as a result of the influence of man-made disasters, climatic conditions, and the influence of harmful production factors. It is a necessary point to select the appropriate textile fabrics and structural design elements to ensure the binding requirements for protective and mechanical properties of the suits. Analysis of the topography of fabrics soiled and damage places will allow designers to choose the optimal constructive and technological solution for the special clothing.

\section{Materials and Methods}

Methods of the study consist of analysis and generalization of data on the range of chemical workers protective clothing and the requirements imposed on it; the analysis of special clothing wear and tear, and contamination topography as a result of the harmful and dangerous factors influence. A functional constructive approach is applied to the development textile fabrics layers systems and elements of the special clothing design.

\section{Literature Review}

The purpose of using chemical protective clothing (CPC) is partly protection or completely insulation a worker from chemical, physical and biological harmful factors. Harmful substances can be found in the form of liquids, sprays, gases, mist, and dust at the chemical, petrochemical, pharmaceutical, agriculture, medicine and other industries (Makarov, 1989; Kohanov, Emelyanova, Nekrasov, 2014; Stull, 2000; Damalas, Koutroubas, 2016; Moser, Dondi, 2015). Chemical burns and poisoning occur as a result of their penetration through damaged areas of textile fabrics and exposure to harmful substances on the skin.

The degree of burn is determined by the chemical activity and toxicity of the substance, its concentration, temperature, and exposure duration. The negative effects of exposure to chemicals can be fast, which manifests itself within the next few hours after direct exposure, or continuous which causes the risk of chronic health complications. For example, at the oil and petrochemical 
industry, petroleum products and oils can contaminate textiles of workwear, and penetrate to inner layers of clothing or the wearer's skin (Aladev, Kovriga).

Skin and subcutaneous tissue damage may occur as a result of frequent contact with oil products. Exposure to dust from coal mining, building construction, different substances processing, mechanical engineering, metallurgy, agriculture, etc., can cause irritation and chronic diseases (Mikhayluts, Pershin, Maksimov, 2005; Kim, Won, Ko, Heo, Chung, 2012; Lim, Koh, 2014). The use of personal protective equipment, including special clothing, is provided in enterprises with a potential threat of exposure to chemical hazardous substances to prevent their harmful effects.

Different requirements apply to special clothing design. It should protect the workers skin from the negative influence of harmful production factors, but at the same time it should not interfere with the normal thermal balance of the body, should be comfortable, provide freedom of movement and be well cleaned from industrial soiling.

The authors considered factors that reduce the quality of fabrics and seams of special clothing during its use. There are various chemical, physical, biological, and mechanical factors can be cause of special clothing fabrics and seams damage: industrial dust, alkalis, acids, solvents, outstanding parts of equipment, sharp elements on the surface of tools and equipment (Van Wely, 2017; Sawada, Kuklane, Wakatsuki, Morikawa, 2017). In the event that the work is related to the maintenance of vehicles or equipment the impact of oil products, operating (including fatcontaining) and cooling liquids, the thermal influence of equipment's heated parts are added to the listed factors (Makarov, 1989; Doctors, Myshkin, 2010; Park, Jang, Shin, 2011).

Operating fluids and oils trapped on textile fabrics increase the amount and fix the permanent retention of dust particles on the fibers (Nikolaenko, Kulevtsov, 2014; Faccini, Vaquero, Amantia, 2012). Careful selection of the protective clothing textiles and design that adequately meet the requirements, depending on the using conditions, is necessary to ensure the protection of workers from these factors. The main requirements for special clothing are: protection against exposure to harmful factors, an increase in the period of time during which the user can work in this clothing, ensuring comfort and freedom of movement.

Realization of these requirements is ensured by fabrics with appropriate properties, as well as by garments design and technological solutions. There are designs, manufacturing technology, textile fabrics for protection suits need to meet varying standards requirements that differ according to CPC purpose.

In accordance with the standard 12.4.279-2014 (EN 14325:2004) the six types of CPC are classified (GOST 12.4.279-2014). The type 1 CPC, fully encapsulated gas-tight suits are divided into several subtypes. The type 2 CPC, non-gas-tight suits that covers the entire body, includes the feet and head. The type 3 CPC, impermeable to liquids suits, covering the whole body and forming impermeable seams clothing (suits, semi-coveralls, coveralls). The type 4 CPC, splash-proof suits, that covers the whole body. The type 5 CPC, suits for protection covering the whole body against airborne solid particulates of chemical substances. The type $6 \mathrm{CPC}$, overall suits with limited protection against liquid chemicals (overalls for short-term and disposable use), covering the whole body. Items that partially cover the human body (aprons, arm sleeves, gowns, jackets, trousers) also obtain.

There are many factors that affect the choice of special clothing: the state of the environment (temperature, humidity) during the working, the duration of work, the type of work functions, the category and state of harmful substances, the permeability of fabrics and seams.

Protection properties, depending from the purpose using of special clothing, and mechanical properties to ensure the required strength (breaking load, abrasion resistance, puncture resistance, etc.) are preferred for protective clothing textiles and design (Abutalipova, Ziyatdinova, Fatkullina, 2010). For example, seams need to check with the strength requirements of the relevant 
standards. Pockets and pocket parts (including pocket lining) need to be made from the same fabrics as the main parts.

Ventilation holes need to not reduce the level of CPC protective properties. Zippers should be hidden or covered with strips of textile fabric from the inside and outside. The fabrics and design of protective clothing need to meet the requirements of ergonomics, reduce the effect of heat stress on the well-being and performance of workers (thermal, hygroscopic properties, air permeability of fabrics), provide freedom and convenience of movement (stiffness, drape ability of fabrics) (Ziyatdinova et al., 2019; Havenith et al., 2011; Sung et al., 2015; Van Wely, 2017; Hajibekova, Tagirova, 2015; Solodov, Ziganshina, 2015; Borodaev, Azanova, Zheltukhin, Abutalipova, Khisamiyeva, 2019).

CPC design and fabrics selection taking into account the balance between the required level of protection and the comfortable state of the workers is the current trend in the design of special clothing. For example, breathable fabrics and lighter nonwovens can be used instead of heavy impermeable rubber- or plastics-coated or laminated fabrics for CPC if there is no risk of skin exposure to toxic chemical vapors.

\section{Results}

The authors identified damaged areas, places of contamination, as well as areas of potential local exposure to chemicals on the surface of workwear taking into account the nature of harmful factors and the nature of their impact. We examined 50 CPC type 6 suits of special clothing for workers of various profession of the petrochemical, gas processing, and processing (production of polymer products) industries. Areas of exposure to harmful production factors and types of damage to workwear fabrics are presented in the table.

Table 1. Areas and types of fabrics damage of special clothing parts as a result of exposure to harmful production factors

\begin{tabular}{|c|c|}
\hline Damage type & Damage area \\
\hline 1 & 2 \\
\hline \multirow[t]{7}{*}{ Abrasion damage } & Neck of the suits \\
\hline & Elbow area of the sleeves \\
\hline & Seat area of the trousers buck halves \\
\hline & The area of the knee folds of the trousers front halves \\
\hline & Bottom of trousers \\
\hline & Bottom of sleeves \\
\hline & Bottom of jacket \\
\hline \multirow[t]{4}{*}{ Tensile or tear damage } & Elbow area of the sleeves \\
\hline & Armhole area in back \\
\hline & Seat area of the trousers buck halves \\
\hline & The area of the knee folds of the trousers front halves \\
\hline \multirow{4}{*}{$\begin{array}{l}\text { Deterioration of appearance and } \\
\text { possible damage as a result of } \\
\text { exposure to industrial contamination } \\
\text { and chemicals }\end{array}$} & The area of the shoulder seams of the front and back \\
\hline & Elbow area of the sleeves \\
\hline & Bottom of sleeves \\
\hline & The central part of the front \\
\hline
\end{tabular}




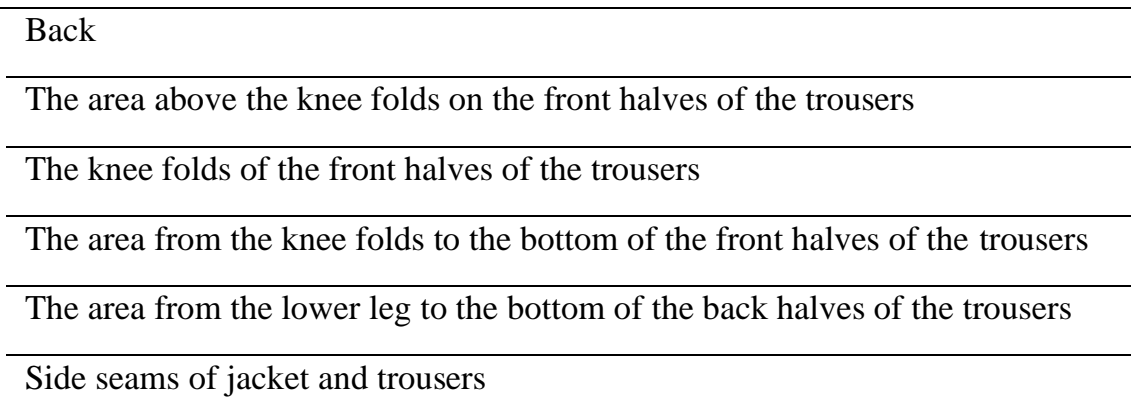

Thus, the three types of local damage of the surface of workwear textiles and seams were identified: damage of the fabric surface and fibers (as a result of abrasive influence); tear of the fabric threads and seams (as a result of tensile and tearing influence), presence of contamination and fabric damage (as a result of exposure to chemicals, oils, oil products, etc.).

\section{Discussion}

Based on the carried out in this work analysis, various solutions can be proposed for combining materials with different properties for various suit designs, depending on the topography of wear. A single-layer package of fabrics is inappropriate to use in the special clothing for chemical enterprises workers, since the fabric can come into direct contact with the skin and increase the degree of exposure to harmful factors on the worker's body. The best option for the systematic design of protective clothing is the multilayer package of fabrics and clothing, as well as varying the fabrics thickness, and the layers number depending on the area of clothing.

As the base fabric, it is necessary to use a fabric that meets the requirements of protection, functionality and strength, and at the same time has a sufficient level of hygienic properties. As additional layer on the outside, in certain areas of the clothing parts, it is possible to use removable and non-removable protective garment detail made from fabrics with a higher level of protective and mechanical properties, or special properties.

For example, polymer-coated materials can be used for the additional protective layer.

As additional intermediate layers, it is possible to use fabrics with special properties, for example, filtering, warm insulating, and others. Textiles with high hygienic properties can be used as an inner layer.

The multilayer package of fabrics with a differentiated inclusion in the design of layers and parts from various fabrics will provide the necessary level of protection for a person, maintain a normal thermal balance of the body and sufficient freedom of movement.

\section{Conclusion}

This work provides a study of the textile soiled and damage places topography and the places of harmful factors impact on the quality and appearance of fabrics to chemical enterprises workers special clothing. The authors suggested a solution for special clothing design, based on the method of models unification. Basic design of the suit model can remain unchanged or change slightly (for example, the shape and location of the pockets changing).

The configuration, location and types of fabrics for protective outer layer can vary depending on the purpose of a particular profession or type of difference various enterprises work, and the functions that protective clothing need to provide. Application of the proposed approach in the design of special clothing will improve the quality and functionality of special and protective clothing, diversify the model range, and reduce the work labor intensity to get ready for production.

\section{References}


Abutalipova, L.N., Ziyatdinova, D.R., Fatkullina, R.R. (2010). The use of expert methods for assessing the quality of protective materials. Shveynaya promyshlennost, 3, 34-36.

Aladev, A.P., Kovriga, E.V. Negative effects of oil and petroleum products for human health. Retrieved from: http://amti.esrae.ru/17-a93

Borodaev, I.A., Azanova, A.A., Zheltukhin, V.S., Abutalipova, L.N., Khisamiyeva, L.G. (2019). The influence of the capacitive coupled radio-frequency discharge on cotton fiber and technological effects of its application. Journal of Physics: Conference Series, 1328, 12033.

Damalas, C.A., Koutroubas, S.D. (2016). Farmers' Exposure to Pesticides: Toxicity Types and Ways of Prevention. Toxics, 4(1), 1. https://doi.org/10.3390/toxics4010001

Doctors, A.V., Myshkin, O.E. (2010). Labor protection at automobile transport enterprises: textbook. Moscow: Alpha-M: INFRA-M.

Faccini, M. Vaquero, C. Amantia, D. (2012). Development of Protective Clothing against Nanoparticle Based on Electrospun Nanofibers. Journal of Nanomaterials. https://doi.org/10.1155/2012/892894

GOST 12.4.279-2014 (EN 14325: 2004). Occupational Safety Standards System (SSBT). Special clothing for protection against chemicals. Classification, specifications, test methods and labeling

Hajibekova, I.A., Tagirova, F.V. (2015). Ensuring the conformity of the designs of special-purpose components to the movements of the human body in order to increase their ergonomic properties. Scientific and methodological electronic journal «Concept», 13, 976-980. Retrieved from: http://e-koncept.ru/2015/85196.htm

Havenith G., Hartog, E., Martini, S. (2011). Heat stress in chemical protective clothing: Porosity and vapour resistance. Ergonomics,54, 497-507. https://doi.org/10.1080/00140139.2011.558638

Khalil, E. (2015). A Technical Overview on Protective Clothing against Chemical Hazards. AASCIT Journal of Chemistry, 2(3), 67-76.

Kim, K.-W., Won, Y.L., Ko, K., Heo, K.-H., Chung, Y. (2012). The Effects of Hazardous Chemical Exposure on Cardiovascular Disease in Chemical Products Manufacturing Workers. Toxicological research, 28, 269-277. https://doi.org/10.5487/TR.2012.28.4.269

Kohanov, V.N., Emelyanova, L.D., Nekrasov, P.A. (2014). Life safety. Moscow: RC INFRA-M.

Lim, J.W., Koh, D. (2014). Chemical Agents that Cause Occupational Diseases. In: The Wiley Blackwell Encyclopedia of Health, Illness, Behavior, and Society. https://doi.org/10.1002/9781118410868.wbehibs399

Makarov, G.V. (1989). Labor protection in the chemical industry. Moscow: Khimiya.

Mikhayluts, A.P., Pershin, A.N., Maksimov, S.A. (2005). The influence of harmful substances on the health of workers in chemical production, occupational and environmental loads. Acta Biomedica Scientifica, 8, 141-144.

Moser, F., Dondi, F. (2015). Environmental protection between chemical practice and applied ethics: A critical review. Toxicological \& Environmental Chemistry, 6, 100-110. https://doi.org/10.1080/02772248.2015.1025786

Nikolaenko, G.R., Kulevtsov, G.N. (2014). Features of the operating conditions of clothing and footwear for special purposes and the requirements for them. Bulletin of Kazan 
Technological University, 5. Retrieved from: https://cyberleninka.ru/article/n/osobennostiusloviy-ekspluatatsii-odezhdy-i-obuvi-spetsialnogo-naznacheniya-i-predyavlyaemye-k-nimtrebovaniya

Park, H., Jang, J.K., Shin, J.A. (2011). Quantitative exposure assessment of various chemical substances in a wafer fabrication industry facility. Safety and Health at Work, 2, 39-51.

Rozdin, I.A., Varenik, O.N., Khabarova, E.I. (2006). Safety of production and labor at chemical plants. Moscow: Koloss.

Sawada, S.I., Kuklane, K., Wakatsuki, K., Morikawa, H. (2017). New development of research on personal protective equipment (PPE) for occupational safety and health. Industrial Health, $55,471-472$.

Solodov, V.A., Ziganshina, M.R. (2015). Anticorrosive properties of epoxy coatings, impregnated with manganese-containing pigments. International Journal of Applied Engineering Research, 10(24), 45383-45391.

Stull, J. (2000). Issues and challenges in chemical protective clothing. Ergonomics of Protective Clothing: European Conference on Protective Clothing, 222-225.

Sung P.-C., Hsu P.-S., Lou S.-Z. (2015). The effects of wearing encapsulating protective clothes, workload, and environment temperature on heat stress. New Ergonomics Perspective. Selected Papers of the 10th Pan-Pacific Conference on Ergonomics, 149-154. https://doi.org/10.1201/b17990-26

Van Wely, E. (2017). Current global standards for chemical protective clothing: how to choose the right protection for the right job? Industrial Health, 55, 485-499.

Ziyatdinova, D.R., Abutalipova, L.N., Vasilyeva, A.Y. (2019). Study of the polymer coating influence on the mechanical properties of protective clothing textiles. Physics of fibrous materials: structure, properties, high technology and materials (Smartex), 207-211. 